\title{
Malaria in North-East India: Importance and Implications in the Era of Elimination
}

\author{
Devojit Kumar Sarma ${ }^{1}$, Pradumnya Kishore Mohapatra ${ }^{2}$, Dibya Ranjan Bhattacharyya ${ }^{2}$, \\ Savitha Chellappan ${ }^{3}$, Balasubramani Karuppusamy ${ }^{4}{ }^{\circ}$, Keshab Barman ${ }^{5}$, \\ Nachimuthu Senthil Kumar ${ }^{6}{ }^{\circ}$, Aditya Prasad Dash ${ }^{7}$, Anil Prakash ${ }^{1, *}$ and \\ Praveen Balabaskaran Nina ${ }^{8, *}$ \\ 1 ICMR-National Institute for Research in Environmental Health, Bhopal, Madhya Pradesh 462030, India; \\ dkbiotek@gmail.com \\ 2 ICMR-RMRC, NE Region, Dibrugarh 786001, Assam, India; pkmdibr@gmail.com (P.K.M.); \\ drbhattacharyya@yahoo.com (D.R.B.) \\ 3 NITM (ICMR), Belagavi 590010, India; savithachellappan@gmail.com \\ 4 Department of Geography, Central University of Tamil Nadu, Tiruvarur 610005, India; geobalas@cutn.ac.in \\ 5 State NVBDCP Unit, Directorate of Health Services, Govt. of Assam, Guwahati 781005, Assam, India; \\ sphc.nvbdcp.assam@gmail.com \\ 6 Department of Biotechnology, Mizoram University, Mizoram 796004, India; nskmzu@gmail.com \\ 7 Central University of Tamil Nadu, Tiruvarur 610005, India; apdash@gmail.com \\ 8 Department of Epidemiology and Public Health, Central University of Tamil Nadu, Tiruvarur 610005, India \\ * Correspondence: anilprakashin@yahoo.co.in (A.P.); praveen@cutn.ac.in (P.B.N.)
}

Received: 7 October 2019; Accepted: 29 November 2019; Published: 10 December 2019

\begin{abstract}
Worldwide and in India, malaria elimination efforts are being ramped up to eradicate the disease by 2030. Malaria elimination efforts in North-East (NE) India will have a great bearing on the overall efforts to eradicate malaria in the rest of India. The first cases of chloroquine and sulfadoxine-pyrimethamine resistance were reported in NE India, and the source of these drug resistant parasites are most likely from South East Asia (SEA). NE India is the only land route through which the parasites from SEA can enter the Indian mainland. India's malaria drug policy had to be constantly updated due to the emergence of drug resistant parasites in NE India. Malaria is highly endemic in many parts of NE India, and Plasmodium falciparum is responsible for the majority of the cases. Highly efficient primary vectors and emerging secondary vectors complicate malaria elimination efforts in NE India. Many of the high transmission zones in NE India are tribal belts, and are difficult to access. The review details the malaria epidemiology in seven NE Indian states from 2008 to 2018. In addition, the origin and evolution of resistance to major anti-malarials are discussed. Furthermore, the bionomics of primary vectors and emergence of secondary malaria vectors, and possible strategies to prevent and control malaria in NE are outlined.
\end{abstract}

Keywords: North-East India; P. falciparum; P. vivax; An. baimaii; An. minimus; artemisinin combination therapy

\section{Introduction}

Despite large-scale global efforts to eradicate malaria in the last few years, it still remains a major public health burden with an estimated 219 million cases and 435,000 deaths worldwide in 2017 [1]. Even though, there were an estimated 3 million fewer cases than in 2016 (216 million), no significant progress was made in reducing the global malaria burden during 2015-2017 [1]. It is estimated that India and 15 sub-Saharan African countries were responsible for $80 \%$ of the world's malaria burden [1]. 
The contribution of India to the world's malaria cases and deaths is estimated to be $4 \%$ [1]. Compared to 2016, India reported a 22\% decrease in cases in 2017 [1], and most came from Odisha [2].

Malaria transmission in India occurs pre-dominantly from either P. falciparum (Pf) or P. vivax (Pv) [3], however, the prevalence of these species varies greatly across different regions of India. There has been a steady increase in $P f$ cases in the last 4 decades, and as of December 2018, Pf was responsible for $48.1 \%$ of malaria cases in India [2]. North-East (NE) Indian states along with Odisha, Chattisgarh and Jharkhand contribute most of the $P f$ cases in the country [2]. NE India alone contributes to $12 \%$ of India's $\mathrm{Pf}$ cases [2].

Assam, Arunachal Pradesh, Meghalaya, Mizoram, Nagaland, Sikkim, Manipur and Tripura make up the eight states of NE India. The state of Sikkim is mostly malaria free, and the few cases reported are thought to be imported cases, and hence will not be discussed. As of 2018, the seven NE states account for $15.2 \%$ of the total malaria cases in India [2]. In India, it is estimated that 162.5 million people live in high-transmission areas [4], which includes many parts of the NE. The hilly and forested areas of NE India are mostly inhabited by the tribal population, and they are at the highest risk of malaria [5]. The distribution of Plasmodium species varies among NE states. Pf is the predominant species in Assam, Mizoram, Tripura and Meghalaya, while Pv is dominant in Nagaland, Arunachal Pradesh and Manipur. Apart from Pf and Pv, the other human malaria parasites, P. ovale and P. malariae have also been recorded from Assam and Arunachal Pradesh [6,7]. The hot and humid climate aided by the numerous hill streams and its tributaries in these tribal areas support perennial mosquito breeding. The primary malaria vectors in NE India are An. minimus and An. baimaii. An. minimus is part of the Minimus Complex that also includes An. harrisoni and An. yaeyamaensis. In NE India, only An. minimus has been reported so far [8]. An. baimaii is part of the An. dirus Complex that includes 7 other sibling species. An. baimaii is the most prevalent sibling species found in NE along with a focal presence of another sibling species, An. dirus X [9]. Apart from these 2 primary vectors, other Anophelines such as An. annularis, An. phillipinensis/nivipes and An. culicifacies are considered to be secondary vectors of malaria in the region [10]. Due to widespread resistance against both chloroquine (CQ) and sulfadoxine-pyrimethamine (SP), artemisinin-lumefantrine (AL) was introduced as the first line anti-malarial against $P f$ in NE Indian states in 2013 [11,12]. The salient features pertaining to malaria in NE India are outlined in Table 1.

Table 1. Salient features of malaria in North-East (NE) India.

\begin{tabular}{|c|c|}
\hline NE States & Assam, Arunachal Pradesh, Mizoram, Tripura, Meghalaya, Nagaland and Manipur \\
\hline Geographical Area & $255,128 \mathrm{Km}^{2}$ (consists of hills, valleys and plains) \\
\hline $\begin{array}{l}\text { National proportion to } \\
\text { land cover }\end{array}$ & $8 \%$ \\
\hline Total Population & 45161611 (2011 census) with an average density of 159 persons $/ \mathrm{km}^{2}$ \\
\hline Climate & Tropical monsoon humid climate \\
\hline Major Plasmodium spp. & P. falciparum and P. vivax \\
\hline Primary malaria vectors & An. baimaii and An. minimus \\
\hline Secondary malaria vectors & An. annularis, An. phillipinensis/nivipes, An. culicifacies etc. \\
\hline
\end{tabular}

Despite being a hot bed for malaria transmission, malaria intervention studies in NE India have been very challenging due to inaccessibility, difficult terrains, forested areas, administrative issues in the inter-state and international border areas, frequent flooding, poor roads and inadequate 
network connectivity [5]. Geography and demography of the region, predominance of $P f$ over $P v$, widespread and early emergence of drug resistance to almost all anti-malarials, and the presence of highly anthropophillic malaria vectors like An. baimaii and An. minimus throughout the region makes it different from the rest of India in terms of malaria control and elimination. In early 2016, the Indian Government announced the national framework for malaria elimination (2016-2030) [13,14]. This is in line with the larger Global Technical Strategy of the World Health Organization (WHO) [15] and Asia Pacific leaders to eliminate malaria by 2030 [16]. Successful malaria intervention strategies in the NE are critical for India's target to eliminate malaria by 2030.

\section{Geography of North-East (NE) States}

The NE is largely a mountainous territory with two-thirds of its area occupied by hilly and mountainous terrain with heights ranging from $50 \mathrm{~m}$ in Brahmaputra valley to $7000 \mathrm{~m}$ above mean sea level in the Himalayan borderland [17]. The states are between $22^{\circ} 00^{\prime}$ to $29^{\circ} 30^{\prime} \mathrm{N}$ and $89^{\circ} 40^{\prime}$ to $97^{\circ} 25^{\prime} \mathrm{E}$, and cover an area of $255,128 \mathrm{Km}^{2}$. The NE shares about $4600 \mathrm{Km}$ of international borders with China (on North), Myanmar (on East), Bangladesh (on South) and Bhutan (On West) (Figure 1). The general climate of the NE is tropical monsoon humid climate. The average temperature during winter is $16^{\circ} \mathrm{C}$, and summer is $30^{\circ} \mathrm{C}$. There is a significant climatic contrast between the valleys and the mountainous region. The NE region receives heavy to very heavy rainfall during the South-West Monsoon season (June to September), and rains peak in June. The average annual rainfall is $2000 \mathrm{~mm}$ with local variations (1500 to 12,000 mm) [18]. Except for Assam, more than half the geographical area of all NE states is forest. The NE is also one of the two biodiversity hotspots in India [19]. The total population of the region is 45,161,611 (2011 census) and the distribution is not homogeneous. The most densely populated parts of NE region are the plains of Brahmaputra, Barak rivers in Assam, the Imphal plain in Manipur and the western part of Tripura [20].

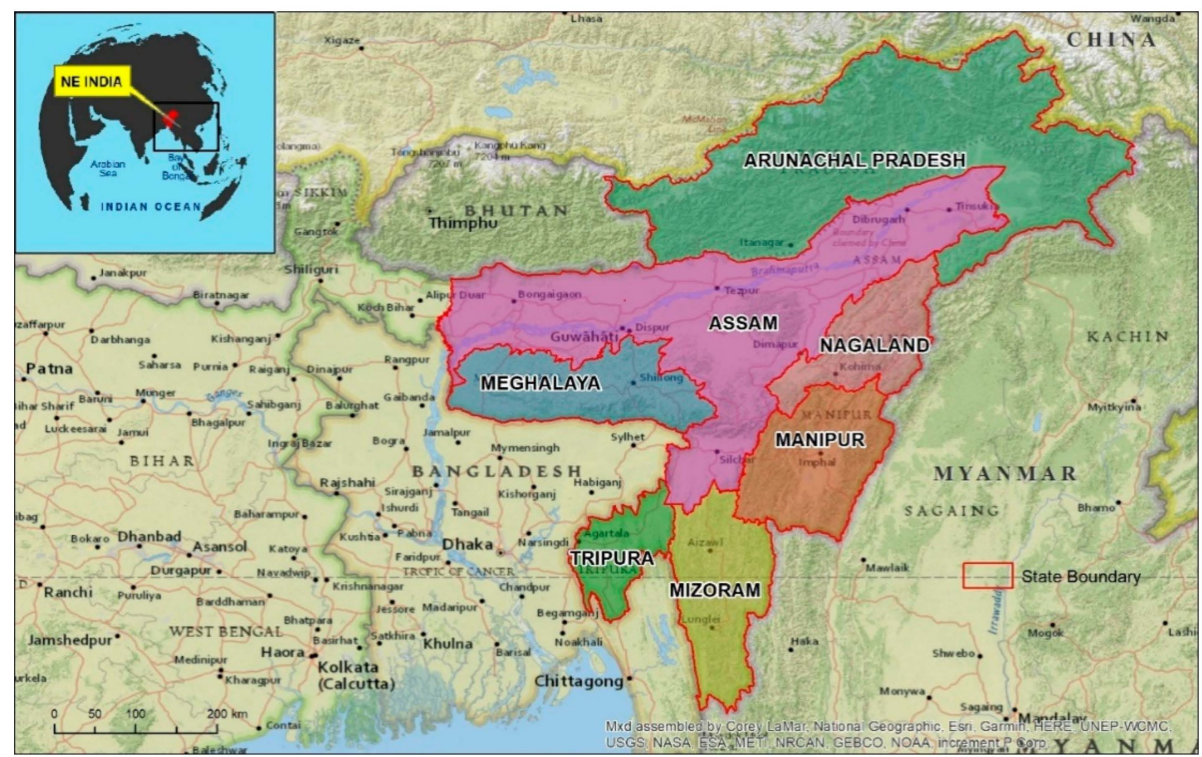

Figure 1. Location map of North-East (NE) India. Red line shows the boundaries of the seven states of NE India.

Assam, located in the central part of NE is considered to be the gateway to NE India as it connects the NE to the Indian mainland by a 22 km strip, called the 'Chicken's Neck', near Siliguri district in West Bengal. Mizoram, Nagaland and Arunachal Pradesh share their international borders with Myanmar (Burma). South East Asia (SEA) is considered to be the hotspot for the generation of drug-resistant parasites. Myanmar is the only land route through which the drug-resistant parasites of SEA can enter India. Thus Mizoram, Nagaland and Arunachal Pradesh, the states bordering Myanmar are 
strategically important as they can serve as a conduit for the drug-resistant parasites from Myanmar to rest of India.

The NE is inhabited by many tribal groups with unique cultural, social and occupational behavior which have a direct role in malaria transmission. Based on topography and socio-demographic conditions, malaria in the NE region can be classified as tribal malaria, forest malaria, border malaria, and organized sector malaria [21].

\section{Malaria Epidemiology (2008 to 2018)}

The NE is co-endemic for both $P f$ and $P v$ with a low-to-moderate transmission intensity resulting in intermediate to stable malaria in the whole region [22]. During the eradication era (late 1950s to early 1960s), the NE along with the other states of India witnessed a steady decline in malaria cases. However, the situation reversed and malaria made a comeback in 1966, and peaked in 1976 with 10.2\% slide positivity rate (SPR) (Figure 2) (See Box A1 for definition of epidemiological parameters) [21]. The surge in malaria cases was due to the emergence of chloroquine resistance (CQR) in $P f$ and its widespread therapeutic failure all over the NE. Since then, both the SPR and slide falciparum rate (SFR) of the NE remained more or less constant until 2008 when CQ was discontinued, and was replaced by artemisinin combination therapy (ACT) as the first line of anti-malarial treatment. Prior to 2008, some major peaks were also observed, and were mostly due to the failure of SP, and emergence of multi-drug resistant parasites in the NE (Figure 2) [11].

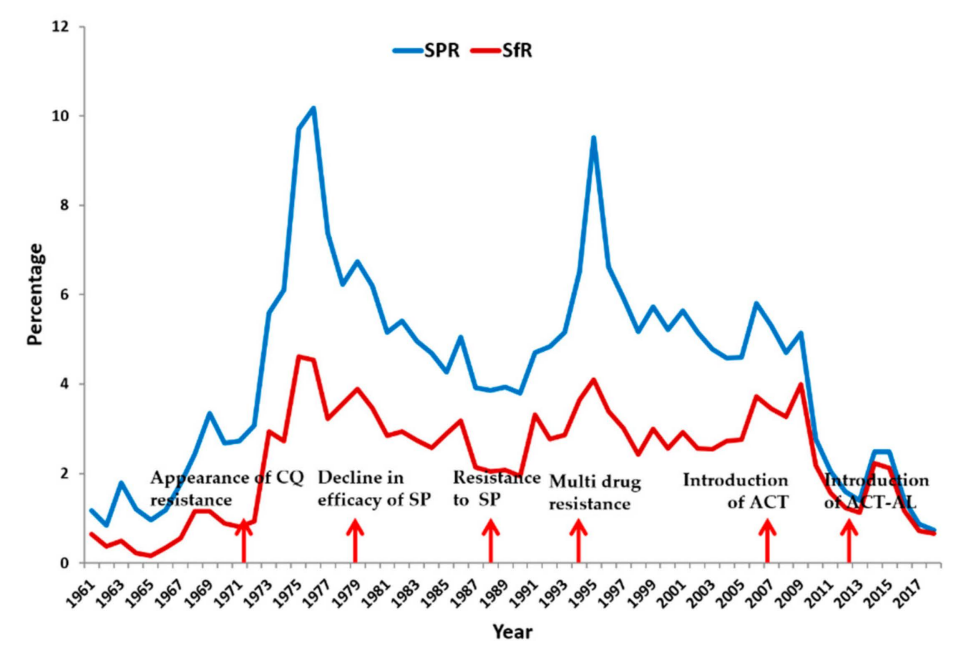

Figure 2. Slide positivity rate (SPR), slide falciparum rate (SFR) and emergence of drug resistance in NE states during 1961-2018. Adapted from Mohapatra et al., 2014 [11].

Malaria epidemiology data (Table 2) obtained from National Vector Borne Disease Control Program (NVBDCP) website from 2008 to 2018 for 7 NE states are shown spatio-temporally in Figure 3. The State Vector Borne Disease Control Program (SVBDCP) unit will collect information of all malaria cases from block primary health centers (PHCs), sub-centers and private hospitals and will send it to NVBDCP, New Delhi, every month. From 2008 to 2012, Assam reported the maximum number of malaria cases, followed by Meghalaya. The maximum number of cases $(91,413, P f-66,557)$ in the study period was observed in Assam followed by Meghalaya (76,759) in 2009. In Assam, from 2009 onwards, there has been a steady decline in malaria cases, and in 2018, the number of cases recorded were 3816 ( $P f-2859)$, below Tripura $(13,079)$ and Meghalaya (6394). In Assam, from a high of 25,815 Pv cases in 2008, there has been a continuous decrease, and in 2018, only 957 cases were reported. As of 2018, Pf and Pv contribute 74.9 and $25.1 \%$ of the cases in Assam. Malaria cases in proportion to population is given in Table 3. Among the NE states, Assam has the highest population density (397 persons/sq km). However, based on the cumulative number of cases during the study period (2008-2018), the number of cases per year $(0.11 \%)$ is comparatively low to the total population. 
Table 2. Distribution of malaria cases in 7 NE states from 2008 to 2018 (Source: National Vector Borne Disease Control Program (NVBDCP), India).

\begin{tabular}{|c|c|c|c|c|c|c|c|c|c|c|c|c|c|c|c|c|c|c|c|c|c|}
\hline \multirow{2}{*}{$\begin{array}{l}\text { States } \\
\text { Year }\end{array}$} & \multicolumn{3}{|c|}{ Assam } & \multicolumn{3}{|c|}{ Arunachal Pradesh } & \multicolumn{3}{|c|}{ Meghalaya } & \multicolumn{3}{|c|}{ Mizoram } & \multicolumn{3}{|c|}{ Nagaland } & \multicolumn{3}{|c|}{ Manipur } & \multicolumn{3}{|c|}{ Tripura } \\
\hline & 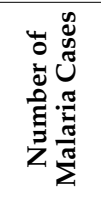 & 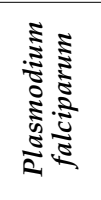 & 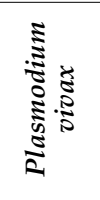 & 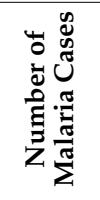 & 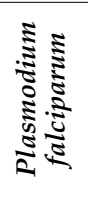 & 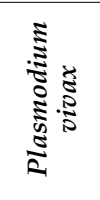 & 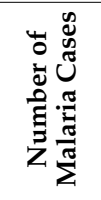 & 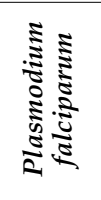 & 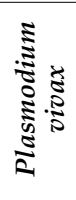 & 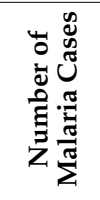 & 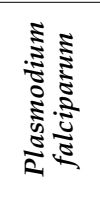 & 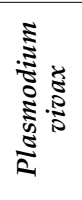 & 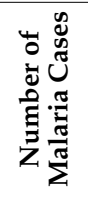 & 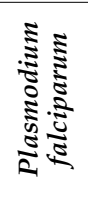 & 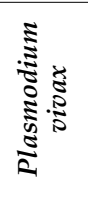 & 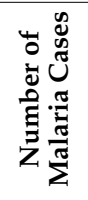 & 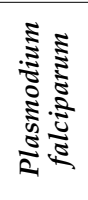 & 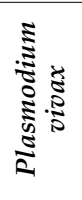 & 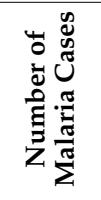 & 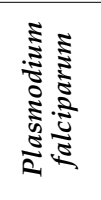 & 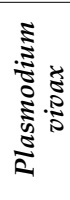 \\
\hline 2008 & 83,939 & 58,124 & 25,815 & 29,146 & 8219 & 20.927 & 39,616 & 36.301 & 3315 & 7361 & 6172 & 1189 & 5078 & 835 & 4243 & 708 & 356 & & 25,894 & 23,588 & 2306 \\
\hline 2009 & 91,413 & 66,557 & 24,856 & 22,066 & 6602 & 15,464 & 76,759 & 74,251 & 2508 & 9399 & 7387 & 2012 & 8489 & 2893 & 5596 & 1069 & 620 & 449 & 24,430 & 22,952 & 1478 \\
\hline 2010 & 68,353 & 48,330 & 20,023 & 17,944 & 5412 & 12,532 & 41,642 & 39,374 & 2268 & 15,594 & 14,664 & 930 & 4959 & 1877 & 3082 & 947 & 487 & 460 & 23,939 & 21,254 & 2685 \\
\hline 2011 & 47,397 & 34,707 & 12,690 & 13,950 & 4856 & 9094 & 25,143 & 24,018 & 1125 & 8861 & 8373 & 488 & 3363 & 950 & 2413 & 714 & 314 & 46 & 14,417 & 13,812 & 605 \\
\hline 2012 & 29,999 & 20,579 & 942 & 8368 & 2789 & 5579 & 20,834 & 19,805 & 1029 & 9883 & 9437 & 446 & 2891 & 821 & 2070 & 255 & 83 & 172 & 11,565 & 10,915 & 650 \\
\hline 2013 & 19,542 & 14,969 & 4573 & 6398 & 2181 & 4217 & 24,727 & 22,885 & 1842 & 11,747 & 10,340 & 1407 & 2285 & 519 & 1766 & 120 & 42 & 78 & 7396 & 6998 & 398 \\
\hline 2014 & 14,540 & 11,210 & 3330 & 6082 & 2338 & 3744 & 39,168 & 37,149 & 2019 & 23,145 & 21,083 & 2062 & 1936 & 647 & 1289 & 145 & 72 & 73 & 51,240 & 49,653 & 1587 \\
\hline 2015 & 15,557 & 11,675 & 3882 & 5088 & 1714 & 3374 & 48,603 & 43,828 & 4775 & 28,593 & 24,602 & 3991 & 1527 & 532 & 995 & 216 & 119 & 97 & 32,525 & 30,074 & 2451 \\
\hline 2016 & 7826 & 5686 & & 3128 & 895 & 2233 & 35,147 & 31,867 & 3280 & 7583 & 5907 & 1676 & 828 & 31 & 51 & 122 & 58 & 64 & 10,546 & 9545 & 1001 \\
\hline 2017 & 5281 & 3494 & 1787 & 1546 & 488 & 1058 & 16,454 & 14,418 & 2036 & 5715 & 4974 & 741 & 394 & 188 & 206 & 80 & 22 & 58 & 7051 & 6571 & 480 \\
\hline 2018 & 3816 & 2859 & 957 & 625 & 154 & 471 & 6394 & 6065 & 329 & 4296 & 3937 & 359 & 113 & 24 & 89 & 12 & 3 & 9 & 13,079 & 12,600 & 479 \\
\hline
\end{tabular}

Table 3. Malaria cases in proportion to population.

\begin{tabular}{|c|c|c|c|c|c|c|c|c|}
\hline State & Pf Cases & $P v$ Cases & Total Cases (2008-2018) & Density (2011) & Population (2011) & Average Cases/Year (2008-2018) & Average Cases to Population & Total Cases to Population \\
\hline Arunachal Pradesh & 35,648 & 78,693 & 114,341 & 17 & $1,382,611$ & $10,394.63$ & $0.75 \%$ & $8.3 \%$ \\
\hline Assam & 278,190 & 109,473 & 387,663 & 397 & $31,169,272$ & $35,242.09$ & $0.11 \%$ & $1.2 \%$ \\
\hline Manipur & 2176 & 2212 & 4388 & 122 & $2,721,756$ & 398.90 & $0.01 \%$ & $0.2 \%$ \\
\hline Meghalaya & 349,961 & 24,526 & 374,487 & 132 & $2,964,007$ & $34,044.27$ & $1.15 \%$ & $12.6 \%$ \\
\hline Mizoram & 116,876 & 15,301 & 132,177 & 52 & $1,091,014$ & $12,016.09$ & $1.10 \%$ & $12.1 \%$ \\
\hline Nagaland & 9602 & 22,261 & 31,863 & 119 & $1,980,602$ & 2896.63 & $0.15 \%$ & $1.6 \%$ \\
\hline Tripura & 207,962 & 14,120 & 222,082 & 350 & $3,671,032$ & $20,189.27$ & $0.55 \%$ & $6.0 \%$ \\
\hline
\end{tabular}




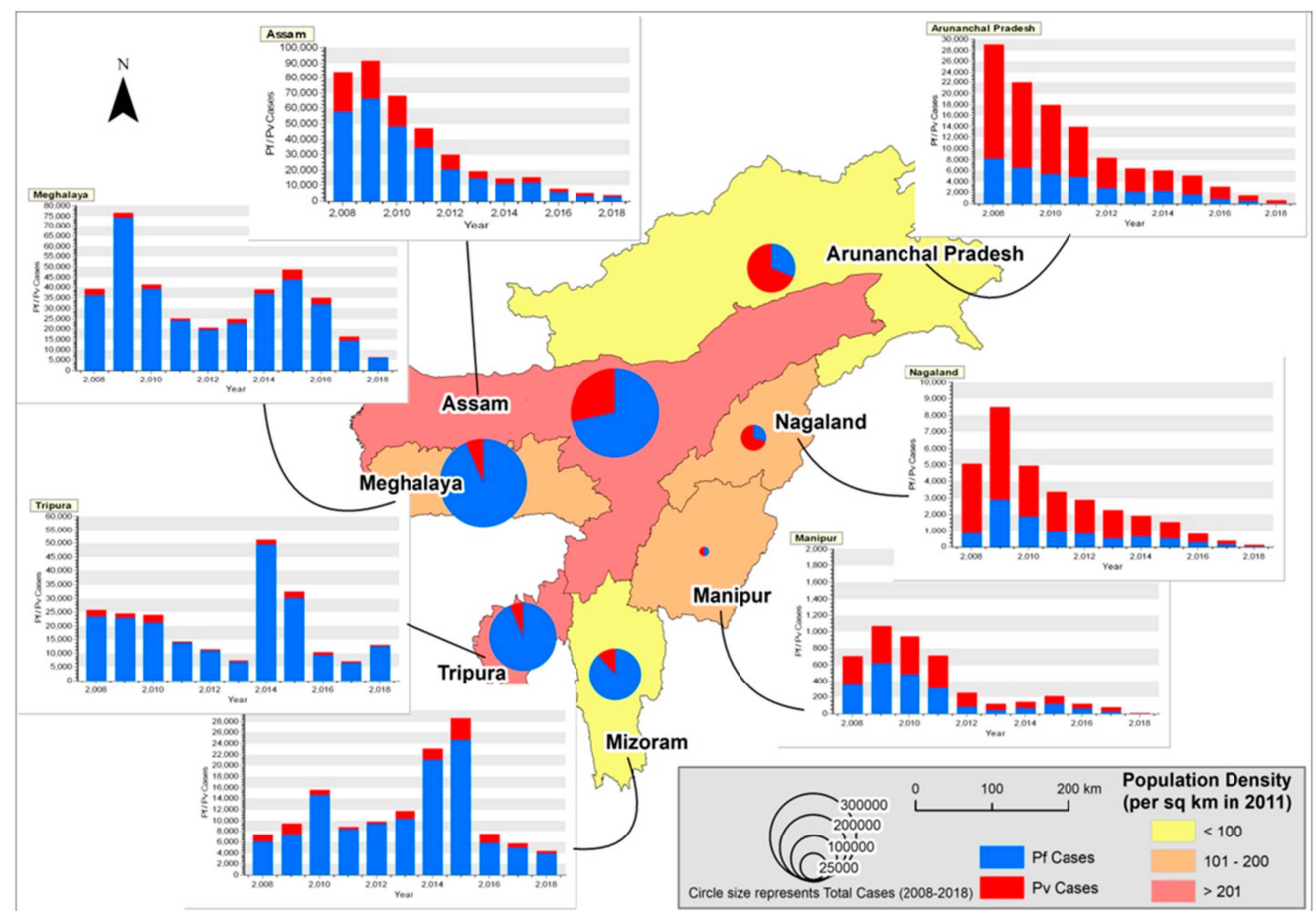

Figure 3. Spatio-temporal distribution of $P f$ and $P v$ cases in NE India during 2008-2018. The background color shows the population density of the states (as per 2011 census). The proportioned pie-chart represents the total number of $P f$ and $P v$ cases reported in the states from 2008 to 2018. (NVBDCP data contains only total malaria cases and $P f$ cases. $P v$ data was obtained by subtracting $P f$ cases from total malaria cases).

Fascinatingly, in Meghalaya, the cases nearly doubled from 39,616 (Pf-36,301) in 2008 to 76,759 in $2009(P f-74,251)$. From a peak of 76,759 cases in 2009, there was a gradual decrease in cases until 2012 $(20,834, P f-19,805)$. From 2013 to 2015, there was a gradual increase in cases $(24,727, P f-22,885$ to 48,603 , $P f-43,828)$, and this was followed by a steady decline until 2018 (6394 cases, $P f-6065)$. Interestingly, $P v$ cases gradually dropped from 2008 (3315) until 2012 (1029), and was followed by an increase in cases from 2013 (1842) until 2015 (4775), and again was followed by a steep decline until 2018 (329). In Meghalaya, as of 2018, Pf and Pv contributed 94.8 and 5.2\% of the cases. Of the $7 \mathrm{NE}$ states, Meghalaya reported the highest proportion of malaria cases (1.15\%/year) to the total population.

In the state of Tripura, there was a steady decline in malaria cases from $2008(25894, P f-23,588)$ to 2013 (7396, $P f$-6998). However, there was a huge malaria epidemic in 2014, and there was a 6.9 fold rise in malaria cases $(51240, P f-49,653)$. Even though there was a gradual decrease from $2015(32,525$, $P f-30,074)$ to 2017 (7051, Pf-6571), malaria cases almost doubled in $2018(13,079, P f-12,600)$. Pf is the leading cause of malaria in Tripura, and contributes to over $90 \%$ of the cases. In 2018, $P v$ contributed to just $3.6 \%$ of the cases. Tripura's proportion of malaria cases per year to the total population is $0.55 \%$, and it ranks fourth in malaria endemicity in the 11 year study period.

In Mizoram, the cases increased from 2008 (7361, Pf-6172) to 2010 (15,594, Pf-14,664), followed by a steep decline in 2011 (8861, $P f$-8373). From 2012, the cases started increasing again, and a peak of 28,593 cases $(P f-24,602)$ was recorded in 2015. There is a decline from $2016(7583, P f-5907)$ to 2018 (4296, Pf-3937). In Mizoram, $P f$ predominates, and was responsible for $91.6 \%$ of the cases. In Mizoram, the population density is 52 persons per $\mathrm{sq} \mathrm{km}$, but the number of cases reported is proportionately very high. Nearly, 1.1 percent of the total population is affected on an average per year, and is the second most malarious state.

The states of Arunachal, Nagaland and Manipur have reported a steady decline in malaria cases from 2009 until 2018, and in 2018, the number of cases reported were 625 (Pf-154, Pv-471), 113 (Pf-24, $P v-89)$ and $12(P f-3, P v-9)$ respectively. Fascinatingly, in Arunachal and Nagaland, $P v$ predominates, 
and in 2018, $P v$ contributed 75.3 and $78.7 \%$ of cases respectively. In Arunachal, the average number of cases to population is $0.75 \%$, and is the third highest among all NE states. In Manipur, over the years, both $P f$ and $P v$ have contributed equally to malaria infections. Manipur has the lowest incidence of malaria as the average number of cases to population is just $0.01 \%$.

$P v$ was more in Arunachal Pradesh, Nagaland and Manipur, the states that border Myanmar, while Pf predominated in Meghalaya, Tripura, Mizoram and Assam, the states that bordered Bangladesh. A declining trend of malaria was observed in Assam, Arunachal Pradesh, Nagaland and Manipur, the states with higher proportion of $P v$ cases. A cyclical trend was observed in Meghalaya, Tripura and Mizoram dominated by $P f$.

\section{Drug Resistance}

Historically, SEA has been a hotspot for the generation of drug-resistant parasites. In the last 50 years, SEA has been a fertile ground for developing resistance against pyrimethamine, $C Q, S P$, quinine, mefloquine, and most worryingly, artemisinins [23]. The only land route through which the parasites of SEA can enter India is through Myanmar. The 4 NE states of India: Mizoram, Manipur, Arunachal and Nagaland share their international borders with Myanmar. Most likely, the drug-resistant parasites originating in SEA would have entered the 4 NE states through Myanmar, and subsequently should have spread to the Indian mainland. CQR originated in the late 1950s in SEA [24], and was first reported in Myanmar (Burma) in 1969. In India, CQR was first reported in the Karbi Anglong district of Assam in 1973 [25]. Following the initial reports of CQR, 13 regional teams were set up in 1978 to monitor anti-malarial resistance through in vivo-efficacy trials [26]. From 1978 to 2007, 54 CQ efficacy studies were carried out in the NE involving 2541 patients, and the treatment failure was 35\% (893) [26]. Across India, CQ treatment failure was observed most in NE, and is the probable locus from which CQR would have spread to eastern, followed by western, parts of India [26]. In 1982, a national drug policy was implemented to improve the management of malaria cases, and established SP as the treatment in CQ-resistant regions [26]. In 2005, for CQ treatment failures, artesunate plus SP replaced $\mathrm{SP}$ alone as the second-line of treatment, and in regions with documented drug resistance, artesunate plus SP was recommended as the first-line of treatment [26]. In 2007, for regions with documented CQ resistance and high-risk districts, artesunate plus SP was selected as the first-line anti-malarial [26]. From 2010 onwards, artesunate plus SP has been the recommended first-line anti-malarial across India [27]. In 2009, nation-wide sentinel sites were set up to monitor anti-malarial drug resistance [28].

The first report of SP resistance was again in Karbi Anglong district of Assam in 1979 [29]. Drug-resistance studies carried out in Assam during 2006 and 2007 identified 12.6\% treatment failure in SP, accompanied by resistant mutations in $d h f r$ and dhps [11]. Artesunate plus SP efficacy studies carried out in three NE states (Mizoram, Tripura and Arunachal Pradesh) in 2012 revealed treatment failure rates of $>10 \%$, necessitating a change in drug policy [12]. From 2013 onwards, artesunate plus $\mathrm{SP}$ was replaced by AL as the first line anti-malarial in NE states, while in the rest of the country, artesunate plus SP continues to remain as the first line of treatment [11,12]. CQ and SP drug-resistance studies carried out in NE are given in Table 4.

The first therapeutic efficacy study on ACT was carried out by Indian Council of Medical Research (ICMR) Regional Medical Research Centre, NE Region, Dibrugarh during 2004-2006 in 4 sites along the Indo-Myanmar border. This is long before ACT was introduced as a first line anti-malarial for treating Pf cases in NE. The study recorded 95.5\% Adequate Clinical and Parasitological Response (ACPR) of ACT with mean parasite clearance time of $55: 17 \pm 14: 26 \mathrm{~h}$. It is significant that $4.5 \%$ of the cases failed ACT (late clinical failure: $2.1 \%$; and late parasitological failure: $2.4 \%$ ) [11]. Later studies have identified the failure in ACT is due to the resistance to the partner drug, SP [11,12]. The genetic determinant of artemisinin (ART) resistance has been linked to mutations in the propeller domain of the kelch protein (Pfkelch13 gene) [30]. Molecular screening of Pfkelch13 by ICMR National Institute of Malaria Research (NIMR) has identified one F446I $(n=85)$ and one R561H $(n=24)$ validated ART resistance marker mutations in the Changlang district of Arunachal Pradesh that borders Myanmar [31,32]. 
In addition, few non-/synonymous mutations (K189T, A578S, and G533A) have also been reported in NE states [31,32]. Both the K189T and A578S mutations were observed in Lunglei district, Mizoram [31]. However, all the reported mutations were not associated with any decline in the clinical efficacy of ACT [31-33].

In vitro ring stage survival assay (RSA) carried out on 12 NE isolates obtained from Assam, Arunachal Pradesh and Tripura found that 8 out of $12(66 \%)$ had a greater than $1 \%$ survival rate [34]. One of the NE isolates from Assam carried an A675V mutation, a candidate/associate marker, but was not associated with the slow clearance phenotype [34]. In addition, 8 of the 12 isolates had an Asn-Asn $(\mathrm{NN})$ insertion between codon 142 and 143 in the Pfkelch13 gene. Worryingly, the first report of partial ART resistance has been in the Purulia, Bankura and Kolkata regions of West Bengal [35], a state that lies in close proximity to Assam. The widespread ART in SEA necessitates the continuous monitoring of the Indo-Myanmar border to aid malaria control and prevention strategies.

Doxycycline has been recommended by NVBDCP as a short-term prophylaxis (less than 6 weeks) for selective groups from non-endemic areas such as military, para-military forces and travelers [36]. However it is rarely used, and no resistance has been observed so far.

The summary of key events related to malaria in the NE is given in Figure 4.

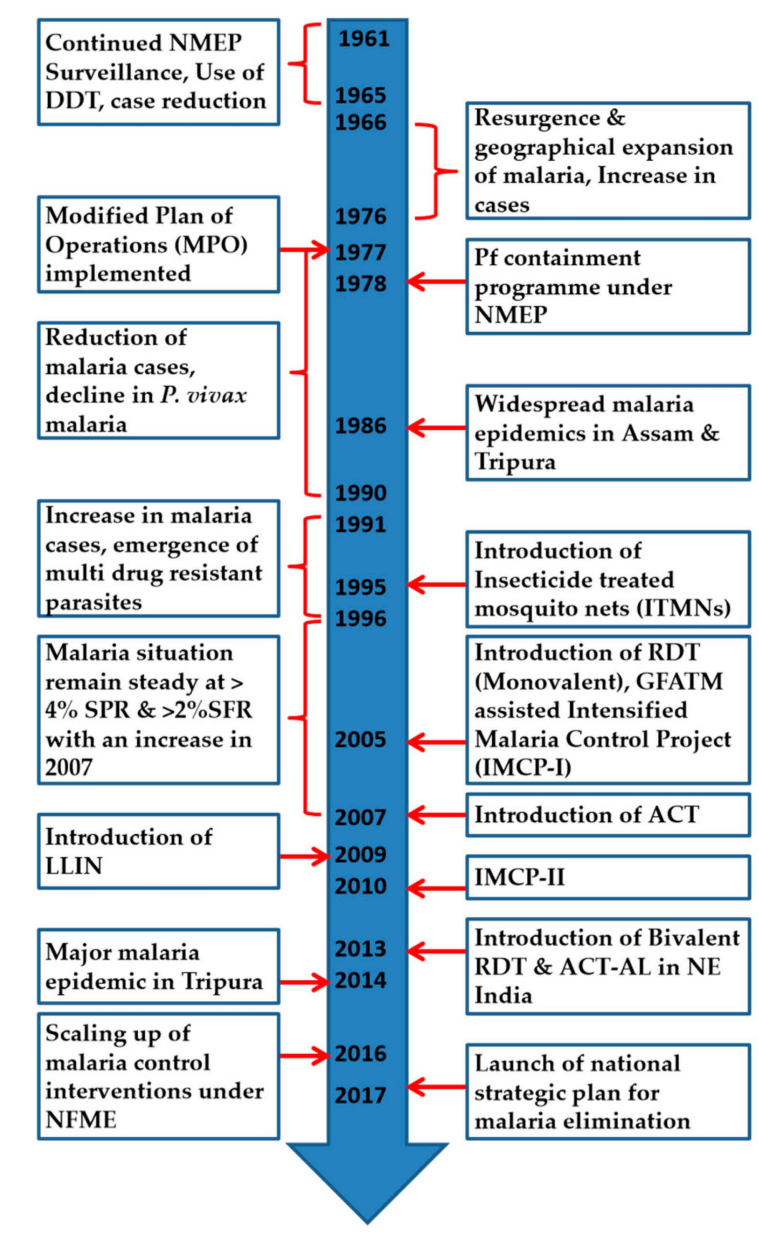

Figure 4. Summary of key events related to Malaria prevention and control in the NE (DDT: Dichlorodiphenyltrichloroethane, NMEP: National Malaria Eradication Program, GFATM: Global Fund to Fight AIDS, Tuberculosis and Malaria, LLIN: Long-lasting insecticide nets, ACT: Artemisinin-based combination therapy, RDT: Rapid diagnostic kit, ACT-AL: ACT Artemether-lumefantrine, NFME: National Framework for Malaria Elimination). 
Table 4. Drug-resistance studies in NE India

\begin{tabular}{|c|c|c|c|c|c|}
\hline Year & Anti-Malarial Drug & Assay Method & State/Area & Outcome & Ref No. \\
\hline \multirow[t]{2}{*}{1973} & CQ & Therapeutic efficacy & Assam & $\begin{array}{c}\text { RI level of resistance in } 52.5 \% \text { and RII } \\
\text { level in } 22.5 \% \text { of cases* }\end{array}$ & [25] \\
\hline & CQ (1500 mg) & 28 days in vivo & Garohills, Meghalaya & RI-33\%, RII-9.5\%, RIII-12.5\% & [37] \\
\hline \multirow{2}{*}{1974} & CQ & Therapeutic efficacy & Assam & RI- $24 \%$ & \multirow{2}{*}{ [38] } \\
\hline & Quinine + pyrimethamine & & & No resistance observed & \\
\hline 1975 & CQ (1500 mg) & 28 days in vivo & Burnihat, Meghalaya & RI-78.3\%, RII-4.3\% & \multirow{2}{*}{ [37] } \\
\hline 1976 & CQ (1500 mg) & 7 days in vivo & Tezu, Lohit, AP & RI-17.9\%, RII-17.9\%, RIII-49.2\% & \\
\hline \multirow{11}{*}{1977} & CQ (900 mg) + Pyrimethamine (50 mg) & \multirow{11}{*}{7 days in vivo } & Assam (different districts) & $0-33.4 \%$ resistance & \multirow{3}{*}{ [39] } \\
\hline & CQ $(600 \mathrm{mg})+$ Pyrimethamine (50 mg) & & Assam (different districts) & 0-90.0\% resistance & \\
\hline & CQ (600 mg) + Pyrimethamine (45 mg) & & Karbi Anglong, Assam & $46 \%$ resistance & \\
\hline & CQ (600 mg) + Pyrimethamine (50 mg) & & \multirow{3}{*}{ Nagaland } & $51.2 \%$ resistance & \multirow{3}{*}{ [40] } \\
\hline & CQ (900 mg) + Pyrimethamine (50 mg) & & & $22 \%$ resistance & \\
\hline & CQ (600 mg) + Pyrimethamine (45 mg) & & & $47 \%$ resistance & \\
\hline & CQ $(1500 \mathrm{mg})$ & & Bama Bazar, Garohills, Meghalaya & S/RI-82.2\%, RIII- $18 \%$ & [37] \\
\hline & CQ $(600 \mathrm{mg})+$ Pyrimethamine $(50 \mathrm{mg})$ & & Miao, AP & $29.9 \%$ resistance & \multirow{4}{*}{ [41] } \\
\hline & CQ $(600 \mathrm{mg})+$ Pyrimethamine $(50 \mathrm{mg})$ & & North Tripura & No resistance observed & \\
\hline & CQ (600 mg) + Pyrimethamine (50 mg) & & Aizawl, Mizoram & $29 \%$ resistance & \\
\hline & CQ (600 mg) + Pyrimethamine (50 mg) & & Jiribam, Manipur & No resistance observed & \\
\hline 1978 & CQ (1500 mg) & 7 days in vivo & Karbi Anglong, Assam & $66.6 \%$ resistance & [39] \\
\hline 1979 & CQ (1500 mg) & 28 days in vivo & Mendipathar, Garohills, Meghalaya & RI-50\% & [37] \\
\hline \multirow{2}{*}{1995} & CQ & 3 days in vivo test & Assam & S/RI-85\%, RI-7\%, RII-3\%, RIII-5\% & [42] \\
\hline & Alpha-Beta Arteether & 28 days therapeutic efficacy & Dibrugarh, Assam & No resistance observed & [43] \\
\hline \multirow{3}{*}{1999} & CQ & 28 days in vivo & Jairampur, AP (Indo-Myanmar Border) & ETF-60.4\%, LTF-22.6\% & \multirow{3}{*}{ [44] } \\
\hline & SP & do & do & ETF- $32.6 \%$, LTF-11.6\% & \\
\hline & quinine & 7 days in vivo & do & $15.8 \%$ treatment failure observed & \\
\hline
\end{tabular}


Table 4. Cont.

\begin{tabular}{|c|c|c|c|c|c|}
\hline Year & Anti-Malarial Drug & Assay Method & State/Area & Outcome & Ref No. \\
\hline \multirow{8}{*}{2001} & $\mathrm{CQ}$ & \multirow{8}{*}{$\begin{array}{l}42 \text { days prospective } \\
\text { randomized non-blinded trial }\end{array}$} & Bokajan, Karbi Anglong, Assam & RI-53\%, RII-2.2\%, RIII-8.9\% & \multirow{8}{*}{ [45] } \\
\hline & SP & & \multirow{7}{*}{ Sonitpur, Assam } & RI-29\%, RII-3.8\%, RIII-5.8\% & \\
\hline & Mefloquine & & & RI-4.4\% & \\
\hline & Mefloquine+artesunate & & & RI-8.7\%, RIII-2\% & \\
\hline & $\mathrm{CQ}$ & & & RI-37.5\%, RII-29\%, RIII- $29 \%$ & \\
\hline & SP & & & RI-36.7\%, RII-14.3\%, RIII-6.1\% & \\
\hline & Mefloquine & & & RI-5.9\%, RII-2\% & \\
\hline & Mefloquine+artesunate & & & RI-1.9\% & \\
\hline \multirow{2}{*}{$2002-2003$} & $\mathrm{CQ}$ & \multirow{2}{*}{28 days in vivo } & $\mathrm{AP}$ & ETF-23.8\%, LCF-14.3\%, LPF-10.7\% & \multirow{2}{*}{ [46] } \\
\hline & SP & & $\mathrm{AP}$ & ETF-14.1\%, LCF-12.6\%, LPF-8.1\% & \\
\hline \multirow{2}{*}{2005} & CQ & 35 days in vivo & Assam & RI-13\%, RII-4\%, RIII-Nil & \multirow{2}{*}{ [47] } \\
\hline & SP & & & No resistance & \\
\hline 2007-2010 & CQ & Molecular (Nested PCR) & Sonitpur, Assam & $\begin{array}{c}\text { pfcrt K76T-72.13\%, pfmdr1 } \\
\mathrm{N} 86 \mathrm{Y}-41.79 \%, \mathrm{~K} 76 \mathrm{~T}+\mathrm{N} 86 \mathrm{Y}-32.7 \%\end{array}$ & [48] \\
\hline 2010 & CQ & In vivo therapeutic efficacy & Tripura (Indo-Bangladesh Border) & $\sim 30 \%$ ETF, $5 \%$ LTF & [49] \\
\hline 2011 & CQ & 28 days in vivo & Tripura & ETF-32.5\%, LCF-35\%, & {$[50]$} \\
\hline
\end{tabular}




\section{Vectors of NE India}

The tropical climate provides a fertile breeding ground for varied mosquito fauna [51]. In India, 61 species of anophelines have been recorded within the subgenera Anopheles and Celia, and there is a possibility of this number increasing with identification of new species under several groups or complexes [52]. Among the 61 Anopheles spp., 9 have been incriminated as malaria vectors in India [53,54]. NE India is part of the "Indo-Burma hot-spot" [55], and is home to diverse fauna and flora. In the early 1990s, Malhotra and Mahanta reported 37 anophelines from NE India [56]. A later survey in early 2000s documented 45 anophelines from this region [P. Dutta, Regional Medical Research Centre, Dibrugarh personal communication]. Anopheles dirus and An. minimus complex mosquitoes are regarded as the main malaria vectors in NE India [8], and these mosquitoes inhabit distinct ecological niches.

The Minimus complex includes three formally named species: An. minimus (earlier species A), An. harrisoni (earlier species C) and An. yaeyamaensis (earlier species E). Present day taxonomy of the An. minimus complex has been resolved by painstaking work of several groups [57-60]. An. minimus was considered to be the most important malaria vector in the entire sub-Himalayan belt. Due to the large-scale application of dichlorodiphenyltrichloroethane (DDT) under the National Malaria Eradication Program (NMEP), this species was thought to have disappeared from this region. However, it re-emerged in the 1980s and was incriminated as a malaria vector in Assam [61,62], Arunachal Pradesh [63], Nagaland [64] and Mizoram [65]. In NE India, only An. minimus s.s. (species A) has been reported [8]. An. minimus is found throughout the year with higher densities between March and August, and is endophagic, endophillic and highly anthropophillic. It bites humans throughout the night, and the peak biting period is between 01:00 to 04:00AM. It breeds in slow-flowing streams with grassy banks [66], and is susceptible to DDT [67]. An. minimus is a highly efficient malaria vector and is responsible for focal disease outbreaks characterized by high $P f$ infections and death in forest fringe and foot hills areas of NE. Even though it is susceptible to DDT, behavioural resistance and avoidance of both DDT and long-lasting insecticide nets (LLIN) have been observed [68].

The Minimus and Fluviatilis complexes are phylogenetically [69] and morphologically closely related and are often misidentified [70]. Originally identified as An. fluviatilis in NE India, it is now recognized as a hyper-melanic form of An. minimus (species A) based on molecular data [70]. Both $A n$. minimus and its hyper-melanic form were found in sympatry during winter season, and were also incriminated in malaria transmission [68].

An. baimaii is the widely prevalent species of An. dirus complex mosquitoes in the entire NE, along with a focal presence of $A n$. dirus X (another unnamed species in the complex) in North Cachar [9]. An. baimaii is a forest-dwelling species found in deep forested areas and in forest borders. High anthropophilicity along with its capacity to bite equally both indoor and outdoor, and resting behavior (outside houses) makes it one of the most efficient primary malaria vectors in SEA including NE [71]. Even though the peak biting time of An. baimaii has been estimated to be from 22:00 to 02:00 $\mathrm{h}$, in the NE it has been observed that human feeding starts from 18:00 h, and an estimated $13 \%$ of biting occurs in the 1st quarter of the night alone [71,72]. An. baimaii inhabits most of the hilly and forested areas of NE bordering Myanmar and Bangladesh, and most of the drug resistant cases have been recorded from these areas. Literature search shows that CQ resistant $P f$ has been commonly associated with An. dirus s.l. [65,73-75]. In NE, An. baimaii is susceptible to many insecticides. Due to its exophillic nature, conventional use of indoor residual insecticides is ineffective, which is also the major reason for sustained transmission of malaria in An. baimaii-dominated areas. Lack of an effective control strategy against $A n$. baimaii is the major reason for its large population size ( $\mathrm{Ne}$ ), high genetic diversity and lack of population bottleneck in its evolutionary history in the NE [76]. The distribution of primary malaria vectors (An. baimaii and An. minimus) of NE is given in Figure 5. Bionomics of primary malaria vectors are given in Table 5 . 


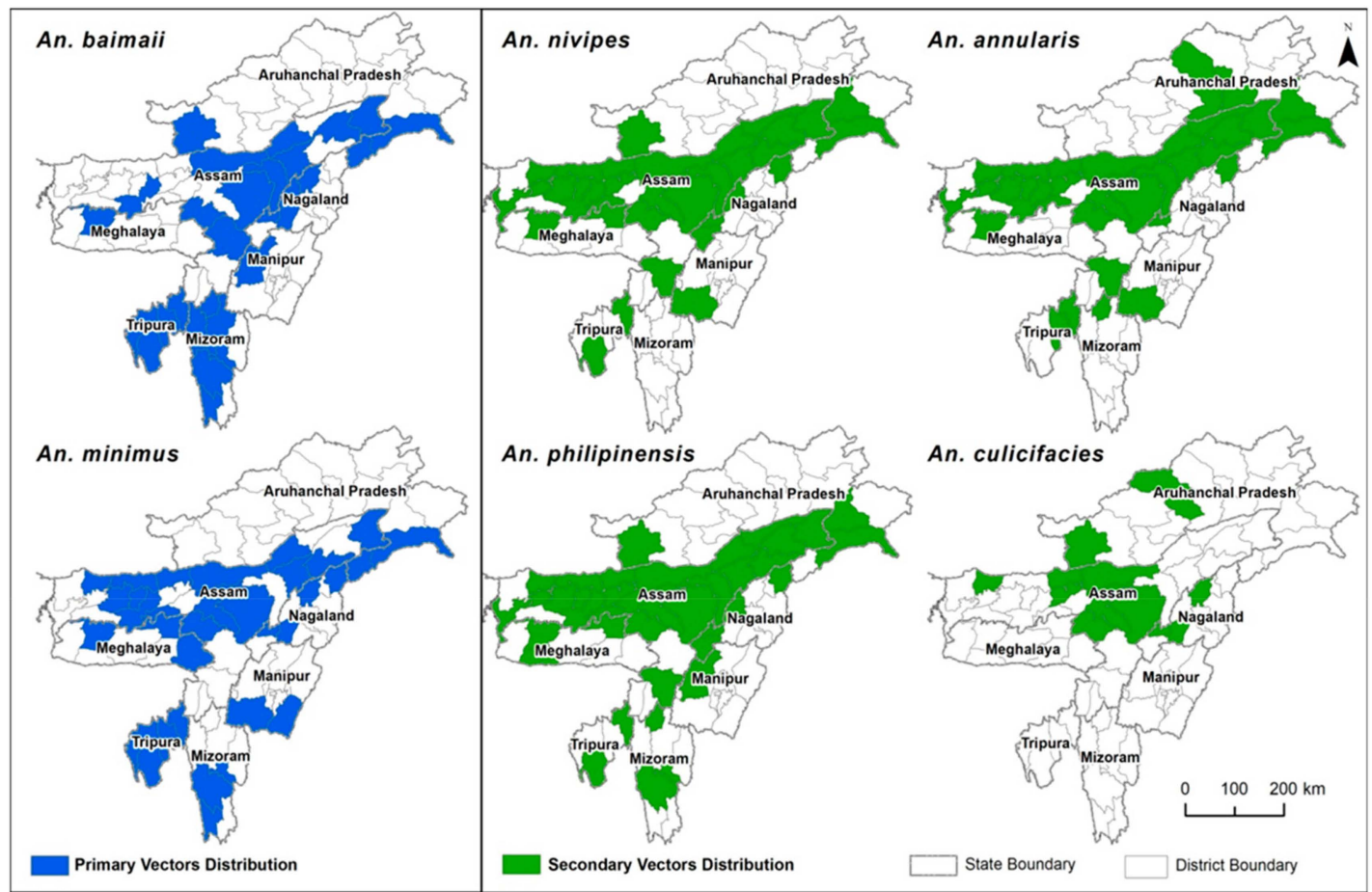

Figure 5. Distribution of primary and secondary malaria vectors in NE India.

\section{Role of Secondary Vectors}

Apart from these 2 primary vectors, An. phillipinensis, An. nivipes, An. annularis, An. culicifacies and $A n$. vagus have been found to play an important and interesting role in malaria transmission, especially in the winter seasons [77]. Sporadic reports of parasite positivity in these species have been reported in the NE ever since 1941, when Anderson and Viswanathan [78] first incriminated An. culicifacies mosquitoes as a malaria vector in Assam. Similarly, An. phillipinensis has been incriminated as a malaria vector from Burnihut area of Meghalaya during 1968-1969 [79] Since then, many other anophelines have been incriminated as malaria vectors in this region (Table 6), however, their actual role in transmission of malaria is still not clear. The distribution of secondary malaria vectors are shown in Figure 5. Another important aspect of these secondary vectors is that most of them display a wide spectrum of metabolic, physiological and behavioral resistance against many insecticides [80-82]. Due to deforestation, shift in agricultural activities, urbanization and climate change, many natural habitats of established malaria vectors are shrinking, and their place has gradually been taken over by other invading species such as An. culicifacies in NE. Therefore, it is important to monitor the vectorial competency of these secondary vectors under changing climate to inform and aid the malaria control program. 
Table 5. Bionomics of major malaria vectors in NE India.

\begin{tabular}{|c|c|c|c|c|c|c|c|c|c|}
\hline \multirow[b]{2}{*}{ Species } & \multirow[b]{2}{*}{$\begin{array}{l}\text { Sibling Species } \\
\text { Present }\end{array}$} & \multirow[b]{2}{*}{ Range } & \multicolumn{5}{|c|}{ Bionomical Characteristics } & \multicolumn{2}{|c|}{ Disease Transmission Relationships } \\
\hline & & & Larval Habitat & $\begin{array}{l}\text { Resting } \\
\text { Habitat }\end{array}$ & Feeding Habit & $\begin{array}{c}\text { Peak Biting } \\
\text { Activity } \\
\text { (hours) }\end{array}$ & $\begin{array}{l}\text { Susceptibility } \\
\text { Status to } \\
\text { Insecticides }\end{array}$ & Density & Infectivity \\
\hline $\begin{array}{l}\text { An. dirus } \\
\text { complex }\end{array}$ & $\begin{array}{l}\text { An. baimaiii (Dirus } \\
\text { D) }[8,9]\end{array}$ & $\begin{array}{l}\text { All NE Indian } \\
\text { states except } \\
\text { for Sikkim [9] }\end{array}$ & $\begin{array}{c}\text { Water pits, } \\
\text { elephant } \\
\text { footprints, rock } \\
\text { bed ravine, mud } \\
\text { pools etc. }\end{array}$ & Outdoor & $\begin{array}{c}\text { Highly } \\
\text { anthropophillic, } \\
\text { both indoor and } \\
\text { outdoor biter [72] }\end{array}$ & 21:00-03:00 & Susceptible [83] & $\begin{array}{c}\text { 5.78\# (1986-1988, } \\
\text { Arunachal Pradesh) [84]; } \\
0.39^{*}(1989-1990, \text { Assam) } \\
\text { [66]; 5.03* (2000-2001, } \\
\text { Assam) [85]; } 1.54 \# \\
\text { (2007-2008, Tripura) [49]; } \\
\text { 4.0-6.0* (2012, Tripura) [83]; } \\
\text { 4.0* (2014, Tripura) [86] }\end{array}$ & $\begin{array}{c}\text { 0.97\% (1986-1988, } \\
\text { Arunachal Pradesh) [84]; } \\
\text { 1.6\% (Aug1995-July1996, } \\
\text { Assam) [87]; 3.2\% (June } \\
\text { 1999 to May 2000, Assam) } \\
\text { [88]; 0.7\% sporozoite rate } \\
\text { (2000, Assam) [85]; 1.9\% } \\
\text { (1995-2000, Assam) [71]; } \\
\text { 11\% (2014, Tripura) [86] }\end{array}$ \\
\hline $\begin{array}{l}\text { An. minimus } \\
\text { complex }\end{array}$ & $\begin{array}{l}\text { An. minimus } \\
\text { (Sibling Sp. A) [8] }\end{array}$ & $\begin{array}{l}\text { All NE Indian } \\
\text { states except } \\
\text { for Sikkim }\end{array}$ & $\begin{array}{l}\text { Perennial foothill } \\
\text { seepage water } \\
\text { streams }\end{array}$ & $\begin{array}{l}\text { Human-dwellings } \\
\text { indoors }\end{array}$ & $\begin{array}{l}\text { Highly } \\
\text { anthropophillic }\end{array}$ & 01:00-04:00 & Susceptible [83] & $\begin{array}{c}\text { 1.86\# (1986-1988, } \\
\text { Arunachal Pradesh) [84]; } \\
0.4^{*} \text { (2014, Tripura) [86] }\end{array}$ & $\begin{array}{c}0.40 \%(1986-1988, \\
\text { Arunachal Pradesh) }[84] \\
0.05 \%(2012, \text { Tripura })[83]\end{array}$ \\
\hline
\end{tabular}


Table 6. Secondary malaria vectors in NE India.

\begin{tabular}{|c|c|c|c|c|c|c|c|}
\hline S1. No. & Year of Incrimination & Month/Season & Place & Species & Total Positivity & Method of Incrimination & Reference \\
\hline 1 & 1941 & Not Known & Assam & An. culicifacies & $0.56 \%$ & Dissection & [78] \\
\hline 2 & 1968 & August & Burnihat, Meghalaya & \multirow{2}{*}{ An. phillipinensis } & 1 no & Dissection & \multirow{2}{*}{ [79] } \\
\hline 3 & 1969 & July & Burnihat, Meghalaya & & 1 no & Dissection & \\
\hline \multirow{9}{*}{4} & \multirow{9}{*}{ 2001-2002 } & \multirow{9}{*}{ Throughout the year } & \multirow{9}{*}{ Jorhat, Assam } & An. aconitus & $3.95 \%$ & \multirow{9}{*}{ CSP ELISA } & \multirow{9}{*}{ [77] } \\
\hline & & & & An. annularis & $5.80 \%$ & & \\
\hline & & & & An. hyrcanus $g p$ & $0.48 \%$ & & \\
\hline & & & & An. jeyporiensis & $6.25 \%$ & & \\
\hline & & & & An. kochi & $1.28 \%$ & & \\
\hline & & & & An. phillipinensis/nivipes & $0.94 \%$ & & \\
\hline & & & & An. tesellatus & $6.67 \%$ & & \\
\hline & & & & An. varuna & $3.23 \%$ & & \\
\hline & & & & An. vagus & $3.87 \%$ & & \\
\hline \multirow{3}{*}{5} & \multirow{3}{*}{ 2000-2002 } & \multirow{3}{*}{ Throughout the year } & Jairampur, AP & \multirow{3}{*}{ An. Phillipinensis/nivipes } & $1.20 \%$ & \multirow{3}{*}{ CSP ELISA } & \multirow{3}{*}{ [89] } \\
\hline & & & Soraipung, DBR, Assam & & $2.60 \%$ & & \\
\hline & & & Titabor, Assam & & $1.70 \%$ & & \\
\hline \multirow{2}{*}{6} & \multirow{2}{*}{ 2008-2009 } & \multirow{2}{*}{ April-October } & Jorhat, Assam & \multirow{2}{*}{ An. nivipes } & $0.70 \%$ & \multirow{2}{*}{ PCR } & \multirow{2}{*}{ [10] } \\
\hline & & & Dimapur, Nagaland & & $0.95 \%$ & & \\
\hline \multirow{9}{*}{7} & \multirow{3}{*}{2012} & \multirow{9}{*}{ Pre \& Post monsoon } & Assam & \multirow{9}{*}{ An. culicifacies } & $2.50 \%$ & \multirow{9}{*}{ CSP ELISA } & \multirow{9}{*}{ [90] } \\
\hline & & & Meghalaya & & $3.50 \%$ & & \\
\hline & & & Manipur & & $1.20 \%$ & & \\
\hline & \multirow{3}{*}{2013} & & Assam & & $10.90 \%$ & & \\
\hline & & & Meghalaya & & $6.40 \%$ & & \\
\hline & & & Manipur & & $1.80 \%$ & & \\
\hline & \multirow{3}{*}{2014} & & Assam & & $6.60 \%$ & & \\
\hline & & & Meghalaya & & $3.50 \%$ & & \\
\hline & & & Manipur & & $9.50 \%$ & & \\
\hline \multirow{3}{*}{8} & \multirow{3}{*}{2013} & & Orang, Assam & An. vagus & $0.56^{*}$ & & \\
\hline & & March-August & Orang, Assam & An. annularis & $0.22^{*}$ & CSP-ICT & [91] \\
\hline & & & Balipara, Assam & An. vagus & $0.13^{*}$ & & \\
\hline
\end{tabular}

$\left({ }^{*}\right.$ Minimum infection rate, CSP: Circumsporozoite protein, ELISA: Enzyme-linked immunosorbant assay, PCR: Polymerase chain reaction, ICT: Immunochromatographic test). 


\section{Conclusions and Future Directions}

Malaria in the NE is highly complex and multi-faceted due to its unique climatic and ecological conditions and, topographic and socio-demographic heterogeneity. In the past, NE has witnessed decline and surge in malaria cases. The significant decline in malaria cases is usually associated with the introduction of new drug or intervention strategies. Also, the emergence of drug resistance, especially to $P f$, has led to a resurgence of malaria in this region. First resistance to CQ and SP in India have been reported from NE, and the origin of these resistant parasites can be traced to SEA. With the threat of ART resistance looming in India, it is critical to step up active surveillance in NE states, especially those that border Myanmar. Strict adherence and compliance to the existing drug policy is critical in preventing and controlling drug resistance in the region.

Epidemiological trend indicates that there has been a gradual decrease in cases over the past 11 years in NE. This decline in malaria cases can be attributed to the combined effect of newer and effective drugs (Artemisinin), effective diagnostic system (use of bivalent RDTs) and implementation of effective mosquito control strategies such as LLINs. Even though the cases have decreased, Assam, Arunachal Pradesh, Tripura and Mizoram continue to be malaria-endemic states. As part of the control strategy, high transmission zones or malaria hot-spots in these regions need to be mapped, and have to be continuously monitored. Malaria hotspots from 2013 to 2016 based on annual parasite incidence (API) at district and PHC level in Assam mapped by Geographic Information system (GIS) are shown in Figure 6. Malaria intervention strategies have to be focused on these mapped high-transmission settings. Similar hot spot mapping have to be carried out in other NE states for effective malaria control and elimination in this region.

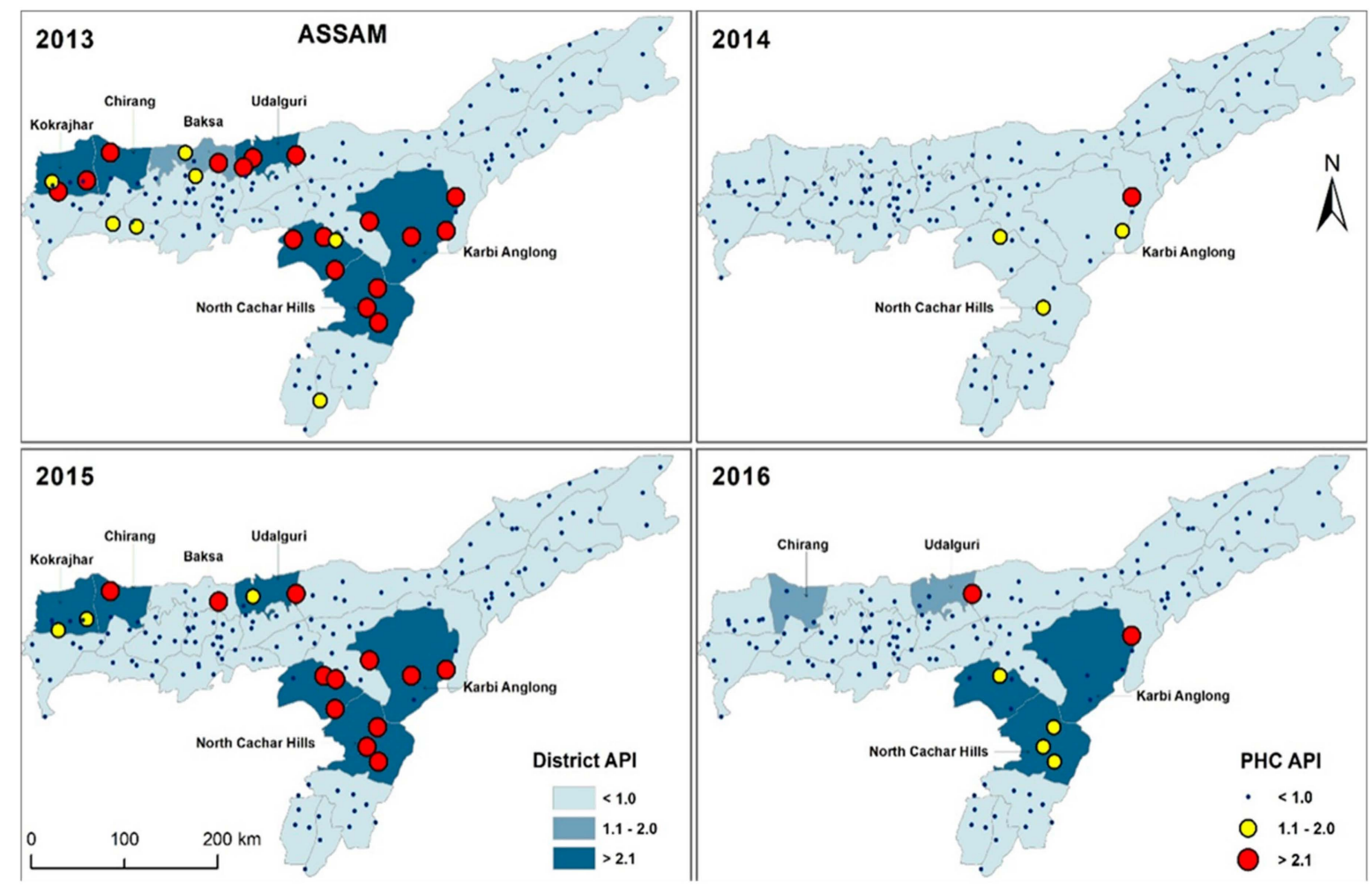

Figure 6. District and primary health center (PHC)-level malaria hotspot in Assam from 2013 to 2016. Malaria hotspots were calculated based on the annual parasite incidence (API) of the respective districts and PHCs.

The true burden of asymptomatic malaria carriers have to be carefully ascertained in these malaria endemic states. Asymptomatic carriers are individuals who carry the malaria parasites without manifesting any clinical symptoms. However, they remain infectious to mosquitoes and continue to 
spread the disease [92], and they are potential threat to malaria elimination efforts [93]. It is estimated that $20 \%-70 \%$ of the infections cannot be detected by conventional microscopy and RDTs [94]. Active surveillance using molecular tools and treatment of asymptomatic carriers should be given high priority as part of malaria elimination efforts in this region.

Even though $P f$ is the major cause of malaria in the malaria-endemic states of Tripura, Meghalaya, Assam and Mizoram, a significant number of cases of $P v$ are reported every year. Furthermore, in the states of Arunachal and Nagaland, $P v$ is the leading cause of malaria. In these states, $P v$ cases were recorded throughout the year with a peak during the rainy season and children less than 5 years old were more affected [22]. It is important to understand the relapse pattern and transmission dynamics of $P v$ in different eco-epidemiological settings for effective control and elimination of $P v$ in the NE. Also, the status of CQR in Pv has to be continuously monitored in all NE states.

Most of the vector biology studies in the NE have focused around An. baimaii and An. minimus, the major malaria vectors. Climate change, deforestation, urbanization and migration have had areat impact on the current habitat of these established malaria vectors. The natural habitat of the primary vectors are shrinking, and in parallel, this has created habitats for new and emerging malaria vectors. Several studies have reported the emergence of secondary malaria vectors in the NE. The vectorial capacity of other Anophelines in different ecological and epidemiological settings of the NE have to be studied to ascertain their role in malaria epidemiology in this region. An. subpictus incriminated as a major malaria vector in Western India [95] has been identified in mosquito epidemiology studies in Mizoram [96]. Substantial focus has to be given to understanding the emergence of new vectors and vector parasite relationships for formulating effective vector-control strategies in this region.

Overall, malaria control and elimination in the NE will be an important step in India's efforts to eradicate malaria in the next decade.

Author Contributions: P.B.N., D.K.S., A.P.D. and A.P. designed the review sections and wrote the manuscript. B.K. drew the maps and S.C. collected the data from past studies. P.K.M., D.R.B., K.B., and N.S.K. contributed significantly in the individual sections of the review.

Funding: This research received no external funding

Acknowledgments: The authors acknowledge the contribution of all public health workers and researchers involved in malaria research in the NE. We are also grateful to the work done by NVBDCP, without which this review is not possible.

Conflicts of Interest: There is no conflict of interest among the authors.

\section{Appendix A}

Box A1. Definition of epidemiological parameters used in malaria.

Annual parasitic incidence (API): Number of new infections per year per 1000 population (Total no. of positive
slides for parasite in a year $\times 1000 /$ Total population. API - (ABER*SPR)/10
Incidence: Number of newly diagnosed malaria cases during a defined period in a specified population
Malaria mortality rate: Number of deaths from malaria per unit of population during a defined period
Prevalence: Proportion of a specified population with malaria infection at one time
Slide positivity rate (SPR): Proportion of blood smears found to be positive for Plasmodium among all blood
smears examined (Total positive $\times 100 /$ Total slides examined)
Slide falciparum rate (SFR): Proportion of blood smears found to be positive for Pf among all blood smears
examined (Total positive Pf $100 /$ Slides examined)


Box A2. Classification of responses to anti-malarial treatment [97].

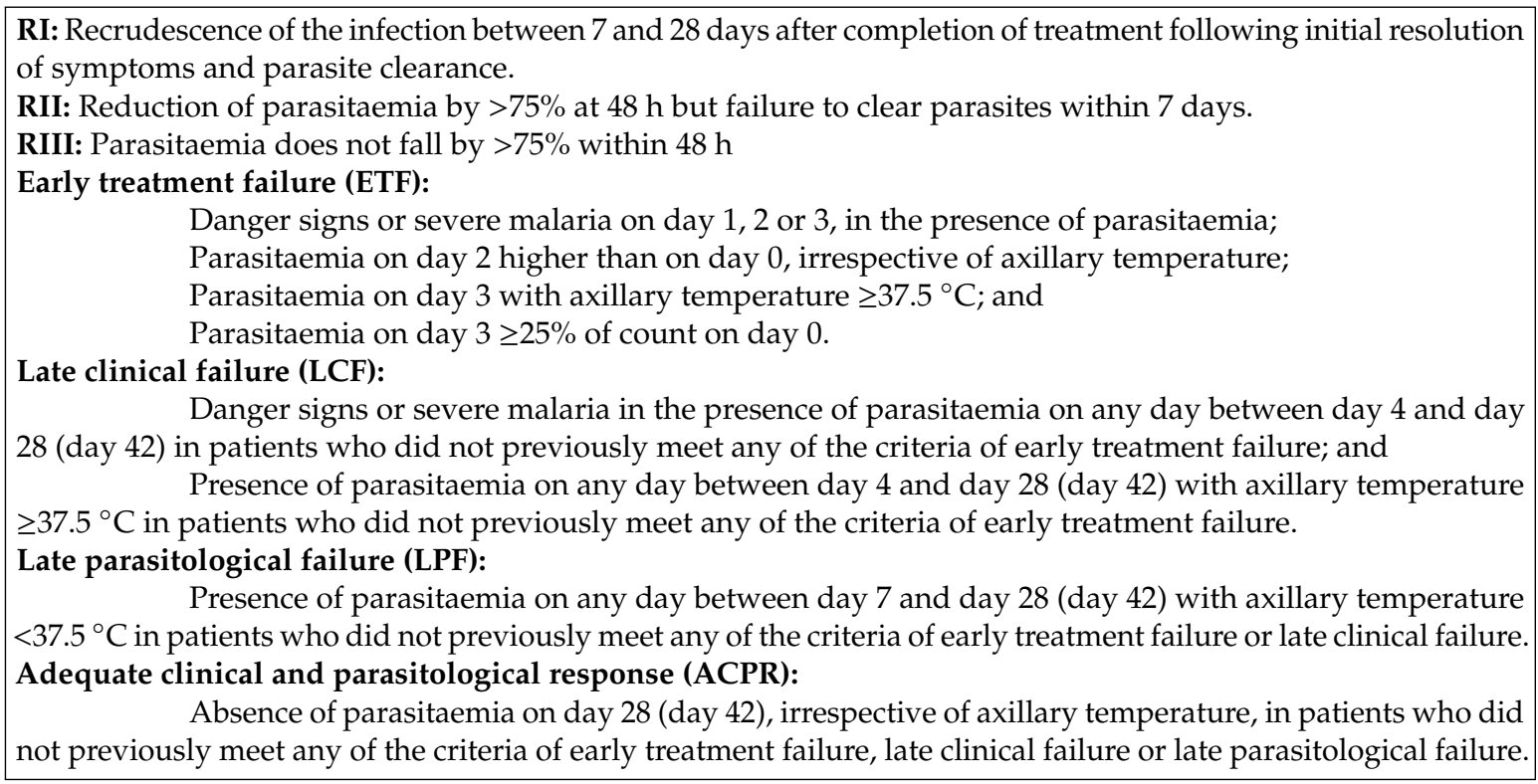

\section{References}

1. WHO. World malaria report; World Health Organization: Geneva, Switzerland, 2018.

2. Available online: https://www.nvbdcp.gov.in/WriteReadData/1892s/95838975781568980798.pdf (accessed on 24 September 2019).

3. Wangdi, K.; Gatton, M.L.; Kelly, G.C.; Banwell, C.; Dev, V.; Clements, A.C.A. Malaria elimination in India and regional implications. Lancet Infect. Dis. 2016, 16, e214-e224. [CrossRef]

4. Available online: https://www.who.int/malaria/publications/country-profiles/profile_ind_en.pdf?ua=1 (accessed on 24 September 2019).

5. Dev, V.; Bhattacharyya, P.C.; Talukdar, R. Transmission of malaria and its control in the northeastern region of India. J. Assoc. Physicians India 2003, 51, 1073-1076. [PubMed]

6. Mohapatra, P.K.; Prakash, A.; Bhattacharyya, D.R.; Goswami, B.K.; Ahmed, A.; Sarmah, B.; Mahanta, J. Detection \& molecular confirmation of a focus of Plasmodium malariae in Arunachal Pradesh, India. Indian J. Med. Res. 2008, 128, 52-56. [PubMed]

7. Prakash, A.; Mohapatra, P.; Bhattacharyya, D.; Goswami, B.K.; Mahanta, J. Plasmodium ovale: First case report from Assam, India. Curr. Sci. 2003, 84, 1187-1188.

8. Prakash, A.; Walton, C.; Bhattacharyya, D.R.; Loughlin, S.O.; Mohapatra, P.K.; Mahanta, J. Molecular characterization and species identification of the Anopheles dirus and An. minimus complexes in north-east India using r-DNA ITS-2. Acta Trop. 2006, 100, 156-161. [CrossRef]

9. Prakash, A.; Sarma, D.K.; Bhattacharyya, D.R.; Mohapatra, P.K.; Bhattacharjee, K.; Das, K.; Mahanta, J. Spatial distribution and r-DNA second internal transcribed spacer characterization of Anopheles dirus (Diptera: Culicidae) complex species in north-east India. Acta Trop. 2010, 114, 49-54. [CrossRef]

10. Bhattacharyya, D.R.; Prakash, A.; Sarma, N.P.; Mohapatra, P.K.; Singh, S.; Sarma, D.K.; Kalita, M.C.; Mahanta, J Molecular evidence for the involvement of Anopheles nivipes (Diptera: Culicidae) in the transmission of Plasmodium falciparum in north-eastern India. Ann. Trop. Med. Parasitol. 2010, 104, 331-336. [CrossRef]

11. Mohapatra, P.K.; Sarma, D.K.; Prakash, A.; Bora, K.; Ahmed, M.A.; Sarma, B.; Goswami, B.K.; Bhattacharyya, D.R.; Mahanta, J. Molecular evidence of increased resistance to anti-folate drugs in Plasmodium falciparum in North-East India: A signal for potential failure of artemisinin plus sulphadoxine-pyrimethamine combination therapy. PLoS ONE 2014, 9, e105562. [CrossRef]

12. Mishra, N.; Kaitholia, K.; Srivastava, B.; Shah, N.K.; Narayan, J.P.; Dev, V.; Phookan, S.; Anvikar, A.R.; Rana, R.; Bharti, R.S.; et al. Declining efficacy of artesunate plus sulphadoxine-pyrimethamine in northeastern India. Malar. J. 2014, 13, 284. [CrossRef] 
13. WHO-SEARO. India Launches the National Framework to Eliminate Malaria; World Health Organization: Geneva, Switzerland, 2016.

14. Ghosh, S.K.; Rahi, M. Malaria elimination in India-The way forward. J. Vector Borne Dis. 2019, 56, 32-40. [CrossRef]

15. WHO. World Malaria Report; World Health Organization: Geneva, Switzerland, 2015.

16. APMEN. Elimination 2030. Asia Pacific malaria elimination network. 2015. Available online: https: //www.apmen.org/web/1/elimination/ (accessed on 24 September 2019).

17. Dikshit, K.R.; Dikshit, J.K. Relief Features of North-East India. In North-East India: Land, People and Economy; Dikshit, K.R., Dikshit, J.K., Eds.; Springer Netherlands: Dordrecht, The Netherlands, 2014; pp. 91-125.

18. Dikshit, K.R.; Dikshit, J.K. Weather and Climate of North-East India. In North-East India: Land, People and Economy; Springer: Dordrecht, The Netherlands, 2014; pp. 149-173.

19. Dikshit, K.R.; Dikshit, J.K. Natural Vegetation: Forests and Grasslands of North-East India. In North-East India: Land, People and Economy; Springer: Dordrecht, The Netherlands, 2014; pp. 213-255.

20. Dikshit, K.R.; Dikshit, J.K. Population of the North-Eastern States of India. In North-East India: Land, People and Economy; Springer: Dordrecht, The Netherlands, 2014; pp. 421-456.

21. Mohapatra, P.K.; Prakash, A.; Bhattacharyya, D.R.; Mahanta, J. Malaria situation in north-eastern region of India. Icmr Bull. 1998, 28, 21-30.

22. Sharma, V.P.; Dev, V.; Phookan, S. Neglected Plasmodium vivax malaria in northeastern States of India. Indian J. Med. Res. 2015, 141, 546-555. [PubMed]

23. Fairhurst, R.M.; Dondorp, A.M. Artemisinin-Resistant Plasmodium falciparum Malaria. Microbiol. Spectr. 2016, 4, 3. [CrossRef] [PubMed]

24. Payne, D. Spread of chloroquine resistance in Plasmodium falciparum. Parasitol. Today 1987, 3, $241-246$. [CrossRef]

25. Sehgal, P.N.; Sharma, M.I.D.; Sharma, S.L.; Gogai, S. Resistance to chloroquine in falciparum malaria in Assam State, India. J. Commun. Dis. 1973, 5, 175-180.

26. Shah, N.K.; Dhillon, G.P.; Dash, A.P.; Arora, U.; Meshnick, S.R.; Valecha, N. Antimalarial drug resistance of Plasmodium falciparum in India: Changes over time and space. Lancet Infect. Dis. 2011, 11, 57-64. [CrossRef]

27. Available online: https://nvbdcp.gov.in/Doc/drug-policy-2010.pdf (accessed on 24 September 2019).

28. Mishra, N.; Singh, J.P.; Srivastava, B.; Arora, U.; Shah, N.K.; Ghosh, S.K.; Bhatt, R.M.; Sharma, S.K.; Das, M.K.; Kumar, A.; et al. Monitoring antimalarial drug resistance in India via sentinel sites: Outcomes and risk factors for treatment failure, 2009-2010. Bull. World Health Organ. 2012, 90, 895-904. [CrossRef]

29. Das, S.B.B.; Roy, J.R.; Guha, A.K.; Rastogi, A.C. Pyrimethamine in combination with sulfadoxine or sulfalene in P. falciparum infected cases in India. Indian J. Malariol. 1981, 18, 109-116.

30. Ariey, F.; Witkowski, B.; Amaratunga, C.; Beghain, J.; Langlois, A.C.; Khim, N.; Kim, S.; Duru, V.; Bouchier, C.; Ma, L.; et al. A molecular marker of artemisinin-resistant Plasmodium falciparum malaria. Nature 2014, 505, 50-55. [CrossRef]

31. Mishra, N.; Bharti, R.S.; Mallick, P.; Singh, O.P.; Srivastava, B.; Rana, R.; Phookan, S.; Gupta, H.P.; Ringwald, P.; Valecha, N. Emerging polymorphisms in falciparum Kelch 13 gene in Northeastern region of India. Malar. J. 2016, 15, 583. [CrossRef]

32. Mishra, N.; Prajapati, S.K.; Kaitholia, K.; Bharti, R.S.; Srivastava, B.; Phookan, S.; Anvikar, A.R.; Dev, V.; Sonal, G.S.; Dhariwal, A.C.; et al. Surveillance of artemisinin resistance in Plasmodium falciparum in India using the kelch13 molecular marker. Antimicrob. Agents Chemother. 2015, 59, 2548-2553. [CrossRef] [PubMed]

33. Mishra, S.; Bharti, P.K.; Shukla, M.M.; Ali, N.A.; Kashyotia, S.S.; Kumar, A.; Dhariwal, A.C.; Singh, N. Clinical and molecular monitoring of Plasmodium falciparum resistance to antimalarial drug (artesunate+sulphadoxine-pyrimethamine) in two highly malarious district of Madhya Pradesh, Central India from 2012-2014. Pathog. Glob. Health 2017, 111, 186-194. [CrossRef] [PubMed]

34. Chakrabarti, R.; White, J.; Babar, P.H.; Kumar, S.; Mudeppa, D.G.; Mascarenhas, A.; Pereira, L.; Dash, R.; Maki, J.N.; Sharma, A.; et al. Decreased in vitro artemisinin sensitivity of Plasmodium falciparum across India. Antimicrob. Agents Chemother. 2019. [CrossRef] [PubMed]

35. Das, S.; Manna, S.; Saha, B.; Hati, A.K.; Roy, S. Novel pfkelch13 Gene Polymorphism Associates With Artemisinin Resistance in Eastern India. Clin. Infect. Dis. Off. Publ. Infect. Dis. Soc. Am. 2019, 69, 1144-1152. [CrossRef] [PubMed] 
36. Anvikar, A. Guidelines for Diagnosis and Treatment of Malaria in India, 2nd ed.; National Institute of Malaria Research: New Delhi, India, 2011.

37. Chakravarty, S.C.; Dwivedi, S.R.; Das, S.; Pukan, D.; Roy, R.G.; Pattanayak, S. Response of Plasmodium falciparum to chloroquine in the Meghalaya state. Indian J. Med. Res. 1979, 70, 34-39. [PubMed]

38. Sehgal, P.N.; Sharma, S.S. Efficacy of quinine with pyrimethamine against chloroquine resistant P. falciparum malaria in Assam State India. J. Commun. Dis. 1974, 6, 175-180.

39. Pattanayak, S.; Roy, R.G.; Phukan, D.; Barkakuty, B.N. Chloroquine resistance in P. falciparum in Assam State. Indian J. Med. Res. 1979, 70, 14-19.

40. Das, S.; Roy, R.G.; Pattanayak, S. A note on chloroquine resistance tests on P. falciparum in Nagaland. Indian J. Med. Res. 1979, 70, 30-33.

41. Pattanayak, S.; Roy, R.G.; Sen, N. Response of Chloroquine with or without pyrimethamine in Plasmodium falciparum in West Bengal, Tripura, Mizoram, Manipur and Arunachal Pradesh. Indian J. Med. Res. 1979, 70, 48-51.

42. Gogoi, S.C.; Dev, V.; Choudhury, B.; Phookan, S. Susceptibility of Plasmodium falciparum to chloroquine in tea garden tribes of Assam, India. Southeast Asian J. Trop. Med. Public Health 1995, 26, 228-230.

43. Mohapatra, P.K.; Khan, A.M.; Prakash, A.; Mahanta, J.; Srivastava, V.K. Effect of arteether alpha/beta on uncomplicated falciparum malaria cases in Upper Assam. Indian J. Med. Res. 1996, 104, 284-287. [PubMed]

44. Mohapatra, P.K.; Namchoom, N.S.; Prakash, A.; Bhattacharya, D.R.; Goswami, B.K.; Mahanta, J. Therapeutic efficacy of anti-malarials in Plasmodium falciparum malaria in an Indo-Myanmar border area of Arunachal Pradesh. Indian J. Med. Res. 2003, 118, 71-76. [PubMed]

45. Campbell, P.; Baruah, S.; Narain, K.; Rogers, C.C. A randomized trial comparing the efficacy of four treatment regimens for uncomplicated falciparum malaria in Assam state, India. Trans. R. Soc. Trop. Med. Hyg. 2006, 100, 108-118. [CrossRef] [PubMed]

46. Mohapatra, P.K.; Prakash, A.; Taison, K.; Negmu, K.; Gohain, A.C.; Namchoom, N.S.; Wange, D.; Bhattacharyya, D.R.; Goswami, B.K.; Borgohain, B.K.; et al. Evaluation of chloroquine (CQ) and sulphadoxine/pyrimethamine (SP) therapy in uncomplicated falciparum malaria in Indo-Myanmar border areas. Trop. Med. Int. Health 2005, 10, 478-483. [CrossRef] [PubMed]

47. Baruah, I.; Talukdar, P.K.; Das, S.C. The drug sensitivities of Plasmodium falciparum in the Sonitpur district, Assam, India. Southeast Asian J. Trop. Med. Public Health 2005, 36, 587-590.

48. Goswami, D.; Dhiman, S.; Rabha, B.; Kumar, D.; Baruah, I.; Veer, V.; Bhola, R.; Sharma, D. High prevalence of pfcrt K76T and mdr1 N86Y mutations in Sonitpur district of Assam, India. J. Parasit. Dis. Off. Organ Indian Soc. Parasitol. 2014, 38, 250-254. [CrossRef]

49. Dhiman, S.; Goswami, D.; Rabha, B.; Gopalakrishnan, R.; Baruah, I.; Singh, L. Malaria epidemiology along Indo-Bangladesh border in Tripura State, India. Southeast Asian J. Trop. Med. Public Health 2010, 41, 1279-1289.

50. Majumdar, T.D.N.; Roy, D.B. Assessment of therapeutic efficacy of chloroquine in uncomplicated Plasmodium falciparum malaria in a rural area of Tripura. J. Pharm. Biomed. Sci. 2011, 10, 1-7.

51. Nagpal, B.N.; Sharma, V.P. Indian anophelines; Science Publishers: Lebanon, NH, USA, 1995.

52. Bhattacharyya, D.; Rajavel, A.; Natarajan, R.; Mohapatra, P.; Jambulingam, P.; Mahanta, J.; Prakash, A. Faunal richness and the checklist of Indian mosquitoes (Diptera: Culicidae). Check List 2014, 10, 1342-1358. [CrossRef]

53. Lal, S.; Sonal, G.S.; Phukar, P.K. Status of malaria in India. J. Indian Acad. Clin. Med. 2000, 5, 19-23.

54. Sharma, V.P. Current scenario of malaria in India. Parassitologia 1999, 41, 349-353. [PubMed]

55. Myers, N.; Mittermeier, R.A.; Mittermeier, C.G.; da Fonseca, G.A.; Kent, J. Biodiversity hotspots for conservation priorities. Nature 2000, 403, 853-858. [CrossRef] [PubMed]

56. Malhotra, P.R.; Mahanta, H.C. Check-List of mosquitoes of Northeast India (Diptera: Culicidae). Orient. Insects 1994, 28, 125-149. [CrossRef]

57. Harbach, R.E.; Parkin, E.; Chen, B.; Butlin, R.K. Anopheles (Cellia) minimus Theobald (Diptera: Culicidae): Neotype designation, characterization, and systematics. Proc. Entomol. Soc. Wash. 2006, 108, 198-209.

58. Harbach, R.E.; Garros, C.; Manh, N.D.; Manguin, S. Formal taxonomy of species C of the Anopheles minimus sibling species complex (Diptera: Culicidae). Zootaxa 2007, 1654, 41-54. [CrossRef]

59. Chen, B.; Harbach, R.E.; Butlin, R.K. Molecular and morphological studies on the Anopheles minimus group of mosquitoes in southern China: Taxonomic review, distribution and malaria vector status. Med. Vet. Entomol. 2002, 16, 253-265. [CrossRef] 
60. Somboon, P.; Rory, A.; Tsuda, Y.; Takagi, M.; Harbach, R. Systematics of Anopheles (Cellia) yaeyamaensis sp. n. alias species E of the An. minimus complex in southeastern Asia (Diptera: Culicidae). Zootaxa 2010, 2651, 43-51. [CrossRef]

61. Kareem, M.A.; Singh, Y.K.; Bhatnagar, V.N.; Krishnamurthy, B.S.; Das, M.; Sharma, G.K. A preliminary report on some entomological observations in malaria endemic areas of Kamrup district, Assam. J. Commun. Dis. $1985,17,29-35$.

62. Prakash, A.; Mohapatra, P.K.; Srivastava, V.K. Vector incrimination in Tamulpur primary health centre, district Nalbari, lower Assam during malaria outbreak 1995. Indian J. Med. Res. 1996, 103, 146-149.

63. Dutta, P.; Baruah, B.D. Incrimination of Anopheles minimus Theobald as a vector of malaria in Arunachal Pradesh. Indian J. Malariol. 1987, 24, 159-162.

64. Bhatnagar, V.N.; Dwivedi, S.R.; Mishra, B.G.; Das, M. Detection and incrimination of Anopheles minimus Theobald 1901 as malaria vector in the foothill areas of Nagaland, India. Indian J. Malariol. 1982, 19, 129-133.

65. Das, S.C.; Baruah, I. Incrimination of Anopheles minimus Theobald and Anopheles balabacensis balabacensis Baisas (A. dirus) as malaria vectors in Mizoram. Indian J. Malariol. 1985, 22, 53-55. [PubMed]

66. Dev, V. Anopheles minimus: Its bionomics and role in the transmission of malaria in Assam, India. Bull. World Health Organ. 1996, 74, 61-66. [PubMed]

67. Prakash, A.; Bhattacharya, D.R.; Mohapatra, P.K.; Mahanta, J. Insecticide susceptibility of Anopheles dirus in Assam. J. Commun. Dis. 1998, 30, 291-292.

68. Dev, V.; Manguin, S. Biology, distribution and control of Anopheles (Cellia) minimus in the context of malaria transmission in northeastern India. Parasites Vectors 2016, 9, 585. [CrossRef]

69. Garros, C.; Harbach, R.E.; Manguin, S. Systematics and biogeographical implications of the phylogenetic relationships between members of the funestus and minimus groups of Anopheles (Diptera: Culicidae). J. Med. Entomol. 2005, 42,7-18. [CrossRef]

70. Singh, O.P.; Nanda, N.; Dev, V.; Bali, P.; Sohail, M.; Mehrunnisa, A.; Adak, T.; Dash, A.P. Molecular evidence of misidentification of Anopheles minimus as Anopheles fluviatilis in Assam (India). Acta Trop. 2010, 113, 241-244. [CrossRef]

71. Prakash, A.; Bhattacharyya, D.R.; Mohapatra, P.K.; Mahanta, J. Malaria transmission risk by the mosquito Anopheles baimaii (formerly known as An. dirus species D) at different hours of the night in North-east India. Med. Vet. Entomol. 2005, 19, 423-427. [CrossRef]

72. Dutta, P.; Bhattacharyya, D.R.; Khan, S.A.; Sharma, C.K.; Mahanta, J. Feeding patterns of Anopheles dirus, the major vector of forest malaria in north east India. Southeast Asian J. Trop. Med. Public Health 1996, 27, 378-381.

73. Dutta, P.; Bhattacharyya, D.R.; Sharma, C.K.; Dutta, L.P. The importance of Anopheles dirus (A. balabacensis) as a vector of malaria in northeast India. Indian J. Malariol. 1989, 26, 95-101.

74. Gould, D.J.; Cadigan, F.C.; Ward, R.A. Falciparum malaria: Transmission to the gibbon by Anopheles balabacensis. Science 1966, 153, 1384. [CrossRef] [PubMed]

75. Yang, T.H. A review of literature on Anopheles balabacensis balabacensis; WHO/MAL/83.999, WHO/MAL/83.878.30; World Health Organization: Geneva, Switzerland, 1983.

76. Sarma, D.K.; Prakash, A.; O'Loughlin, S.M.; Bhattacharyya, D.R.; Mohapatra, P.K.; Bhattacharjee, K.; Das, K.; Singh, S.; Sarma, N.P.; Ahmed, G.U.; et al. Genetic population structure of the malaria vector Anopheles baimaii in north-east India using mitochondrial DNA. Malar. J. 2012, 11, 76. [CrossRef] [PubMed]

77. Prakash, A.; Bhattacharyya, D.R.; Mohapatra, P.K.; Mahanta, J. Role of the prevalent Anopheles species in the transmission of Plasmodium falciparum and P. vivax in Assam state, north-eastern India. Ann. Trop. Med. Parasitol. 2004, 98, 559-568. [CrossRef] [PubMed]

78. Anderson, L.A.P.; Viswanathan, D.K. The Assam Medical Research Society, Shillong: A resume on its activities during 1931-1941. Calcatta:ThackerSpink Co. 1943. Available online: https://www.cabdirect.org/ cabdirect/abstract/19431000207 (accessed on 24 September 2019).

79. Rajagopal, R. Studies on persistent transmission of malaria in Burnihat, Meghalaya. J. Commun. Dis. 1976, 8, 235-245.

80. Dev, V.; Sharma, V. The Dominant Mosquito Vectors of Human Malaria in India, Anopheles mosquitoes-New insights into malaria vectors, Sylvie Manguin. In Anopheles Mosquitoes, New Insights Into Malaria Vectors; Manguin, S., Ed.; IntechOpen: Rijeka, Croatia, 2013; Available online: https://www.intechopen.com/books/anopheles-mosquitoes-new-insights-into-malaria-vectors/thedominant-mosquito-vectors-of-human-malaria-in-india (accessed on 24 September 2019). 
81. Dhiman, S.; Rabha, B.; Goswami, D.; Das, N.G.; Baruah, I.; Bhola, R.K.; Veer, V. Insecticide resistance and human blood meal preference of Anopheles annularis in Asom-Meghalaya border area, northeast India. J. Vector Borne Dis. 2014, 51, 133-136. [PubMed]

82. Raghavendra, K.; Velamuri, P.S.; Verma, V.; Elamathi, N.; Barik, T.K.; Bhatt, R.M.; Dash, A.P. Temporo-spatial distribution of insecticide-resistance in Indian malaria vectors in the last quarter-century: Need for regular resistance monitoring and management. J. Vector Borne Dis. 2017, 54, 111-130. [PubMed]

83. Dev, V.; Adak, T.; Singh, O.P.; Nanda, N.; Baidya, B.K. Malaria transmission in Tripura: Disease distribution \& determinants. Indian J. Med. Res. 2015, 142, S12-S22.

84. Dutta, P.; Bhattacharyya, D.R.; Sharma, C.K.; Dutta, L.P. Anopheline fauna of parts of Tirap district, Arunachal Pradesh with reference to malaria transmission. Indian J. Med. Res. 1992, 95, 245-249.

85. Prakash, A.; Bhattacharyya, D.R.; Mohapatra, P.K.; Barua, U.; Phukan, A.; Mahanta, J. Malaria control in a forest camp in an oil exploration area of Upper Assam. Natl. Med. J. India 2003, 16, 135-138.

86. Sarmah, N.; Bhowmik, I.; Sarma, D.; Sharma, C.; Medhi, G.; Mohapatra, P.; Mahanta, J.; Bhattacharyya, D. Role of Anopheles baimaii: Potential vector of epidemic outbreak in Tripura, North-east India. J. Glob. Health Rep. 2019, 3. [CrossRef]

87. Prakash, A.; Bhattacharyya, D.R.; Mohapatra, P.K.; Mahanta, J. Seasonal prevalence of Anopheles dirus and malaria transmission in a forest fringed village of Assam, India. Indian J. Malariol. 1997, 34, 117-125. [PubMed]

88. Prakash, A.; Bhattacharyya, D.R.; Mohapatra, P.K.; Mahanta, J. Estimation of vectorial capacity of Anopheles dirus (Diptera: Culicidae) in a forest-fringed village of Assam (India). Vector Borne Zoonotic Dis. 2001, 1, 231-237. [CrossRef] [PubMed]

89. Prakash, A.; Bhattacharyya, D.R.; Mohapatra, P.K.; Mahanta, J. Potential of Anopheles philippinensis-nivipes complex mosquitoes as malaria vector in north-east India. J. Environ. Biol. 2005, 26, 719-723. [PubMed]

90. Akhtar, N.; Nagpal, B.N.; Kapoor, N.; Srivastava, A.; Valecha, N. Role of An. culicifacies as a vector of malaria in changing ecological scenario of Northeastern states of India. J. Vector Borne Dis. 2016, 53, $264-271$. [PubMed]

91. Dhiman, S.; Yadav, K.; Rabha, B.; Goswami, D.; Hazarika, S.; Tyagi, V. Evaluation of Insecticides Susceptibility and Malaria Vector Potential of Anopheles annularis s.l. and Anopheles vagus in Assam, India. PLoS ONE 2016, 11, e0151786. [CrossRef] [PubMed]

92. Lindblade, K.A.; Steinhardt, L.; Samuels, A.; Kachur, S.P.; Slutsker, L. The silent threat: Asymptomatic parasitemia and malaria transmission. Expert Rev. Anti-Infect. Ther. 2013, 11, 623-639. [CrossRef]

93. Sattabongkot, J.; Suansomjit, C.; Nguitragool, W.; Sirichaisinthop, J.; Warit, S.; Tiensuwan, M.; Buates, S. Prevalence of asymptomatic Plasmodium infections with sub-microscopic parasite densities in the northwestern border of Thailand: A potential threat to malaria elimination. Malar. J. 2018, 17, 329. [CrossRef]

94. Poirot, E.; Skarbinski, J.; Sinclair, D.; Kachur, S.P.; Slutsker, L.; Hwang, J. Mass drug administration for malaria. Cochrane Database Syst. Rev. 2013, 12, CD008846. Available online: https://pubmed.ncbi.nlm.nih. gov/24318836-mass-drug-administration-for-malaria (accessed on 24 September 2019). [CrossRef]

95. Kumar, A.; Hosmani, R.; Jadhav, S.; de Sousa, T.; Mohanty, A.; Naik, M.; Shettigar, A.; Kale, S.; Valecha, N.; Chery, L.; et al. Anopheles subpictus carry human malaria parasites in an urban area of Western India and may facilitate perennial malaria transmission. Malar. J. 2016, 15, 124. [CrossRef]

96. Zomuanpuii, R.; Ringngheti, L.; Brindha, S.; Gurusubramanian, G.; Senthil Kumar, N. ITS2 characterization and Anopheles species identification of the subgenus Cellia. Acta Trop. 2013, 125, 309-319. [CrossRef]

97. Rieckmann, K.H. Monitoring the response of malaria infections to treatment. Bull. World Health Organ. 1990, 68, 759-760. [PubMed]

(C) 2019 by the authors. Licensee MDPI, Basel, Switzerland. This article is an open access article distributed under the terms and conditions of the Creative Commons Attribution (CC BY) license (http://creativecommons.org/licenses/by/4.0/). 